\title{
الحركة الطلابية الإسلامية في فلسطين- النشأة والدور والتحديات
}

\author{
معاذ إبراهيم عتيلي \\ طالب في مرحلة الدكتوراه في قسم الدعوة والقيادة في الجامعة الوطنية الماليزية- ماليزيا \\ muathateeli@gmail.com \\ محمد فيصل أشعري \\ محاضر في قسم الدعوة والقيادة في الجامعة الوطنية الماليزية- ماليزيا
}

إن الدور الكبير الذي تقوم به الحركة الطلابية الفلسطينية منذ نشأهها بوصفها رافعة متينة للعمل الوطني والطلابي في

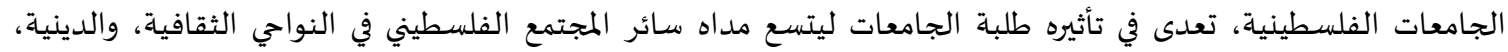

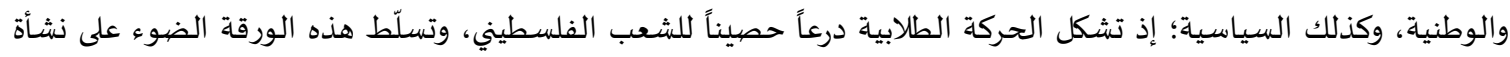

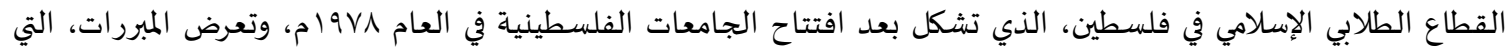

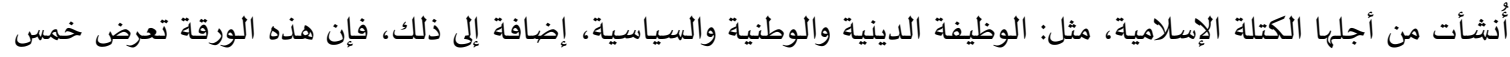

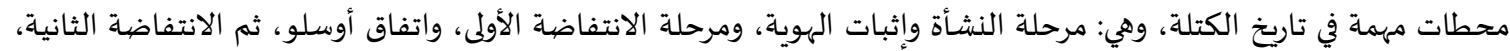

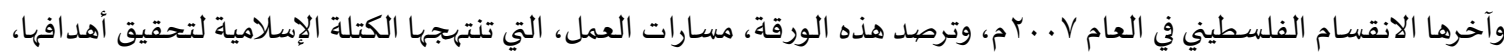
مثل: المسارات الخدمية، والنقابية، والدينية، والوطنية وغيرها.

الكلمات المفتاحية: الحركة الطلابية الإسلامية، انتفاضة 19NV م، اتفاق أوسلو، انتفاضية الأقصى، الانقسام الفلسطيني. @) (1)

الحمد لله رب العالمين، والصلاة والسلام على سيدنا محمد وعلى آله وصحبه أجمعين، وبعد:

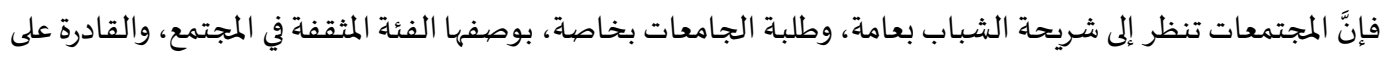

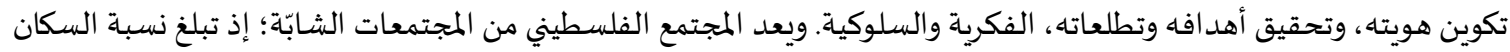

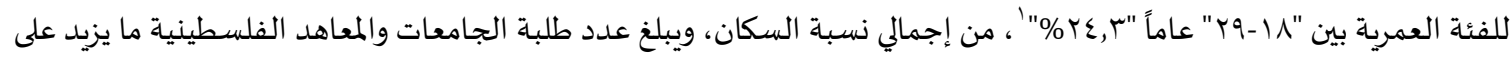

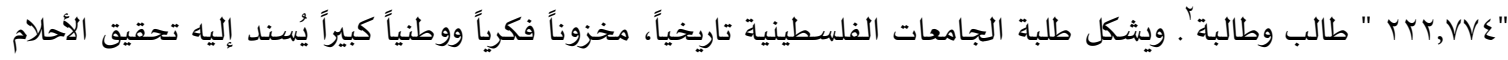

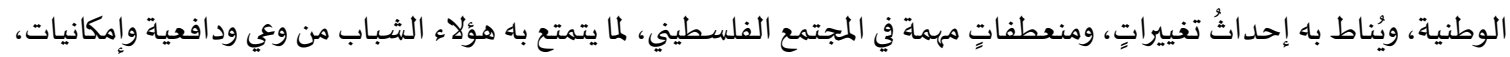

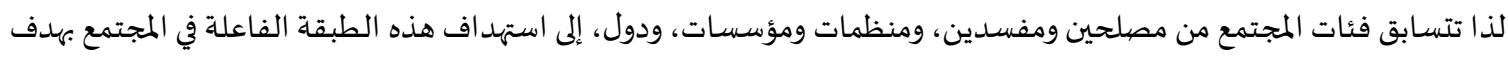

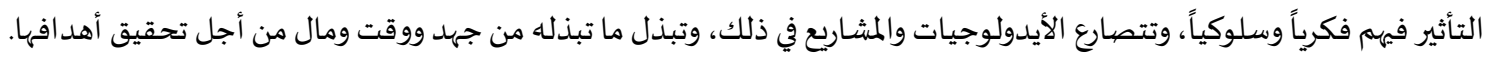

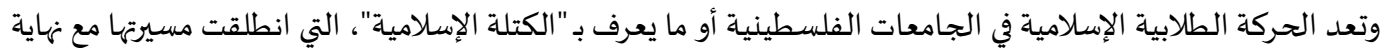

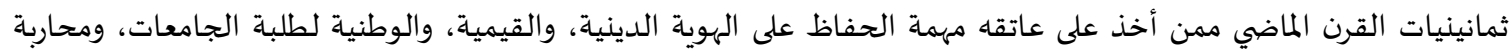

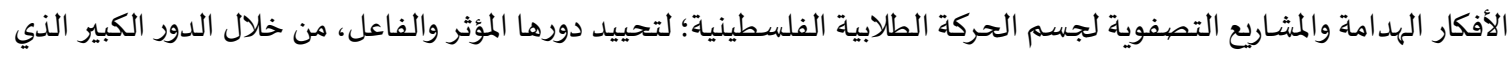

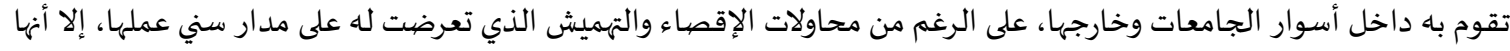

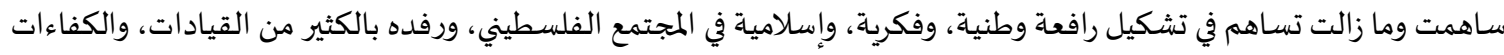


كان لنشأة الجامعات الفلسطينية في الضفة الغربية وقطاع غزة في سبعينيات القرن الماضي محطة مهمة في تاريخ الحركة

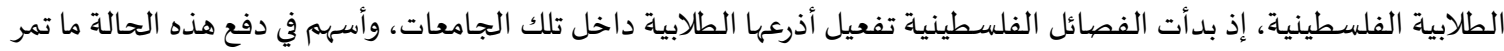

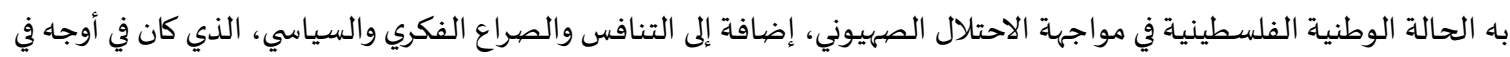
تلك الفترة، ذلك كله، هيأ الظروف أمام تأسيس القطاع الطلابي للحركة الإسلامية في جامعات فلسطين.

مشكلة الدراسـة: إنَّ الدور الكبير والمؤثر، الذي تلعبه الأطر الطلابية الفلسطينية على الصعيد الطلابي والوطني والمجتمعي، يجعل من هذه الأطر محل اهتمام ورعاية من جهة، واستهداف من جهة أخرى؛ فعلى صعيد الاهتمام تسعى مكونات المجتمع الفلسطيني الوطنية

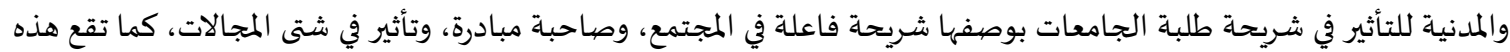
الفئة بالمقابل لحالة استهداف ومحاولات تحييد الحركة الطلابية الفلسطينية عن دورها الريادي المنوط بها، وعلى رأسها الفعل الوطني ولئي

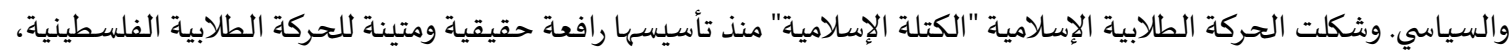
ولعبت الكتلة الإسلامية في الجامعات دوراً متميزاً لم يقتصر تأثيره داخل أسوار الجامعات الفلسطينية، وتسعى الكتلة الإسلامية من

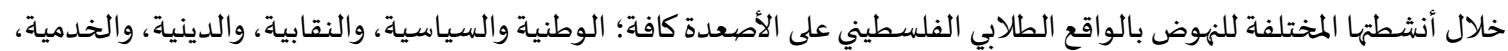
والثقافياة، وغيرها. وتأتي هذه الدارسة لرصد أنشطة الكتلة الإسلامية في جامعات فلسطين، واتجاهات عمل تلك الأنشطة وأوزانها،

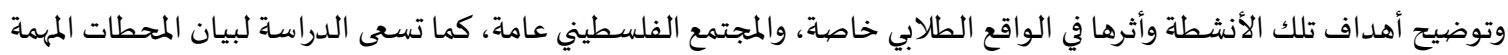
في تاريخ الكتلة الإسلامية منذ تأسيسها.

أهداف الدراسـة:

تهدف هذه الدراسة إلى تحقيق ثلاثة أهداف رئيسية متمثلة في: ا. بيان تارتخ تأسيس الحركة الطلابية الإسلامية في الجامعات الفلسطينية والتأصيل الزماني والمكاني لها، وتوضيح أبرز المنعطفات التاريخية، التي مرت بها الكتلة الإسلامية منذ تأسيسها.

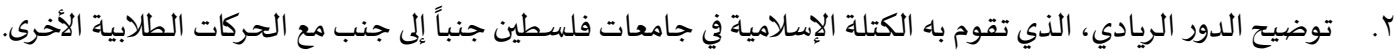
r. رصد اتجاهات عمل الكتلة الإسلامية في الجامعات الفلسطينية وبيان مساراتها وأنواعها.

أهمية الدراسـة:

تكمن أهمية هذه الدراسة في معالجتها لدور إطار طلابي مؤثر في الجامعات الفلسطينية وهو الكتلة الإسلامية، التي تعلب دوراً مهماً وبارزاً في النهوض بالواقع الطلابي الفلسطيني بشكل خاص، والمجتمع الفلسطيني بشكل عام، إذ تعد الحركات الطلابية الفلسطينية مركزاً مهماً للحركات الوطنية الفلسطينية، وكذلك المجتمع المدني والمؤسسات المجتمعية، حئه حيث تأتي هذه الدراسة للبحث في دور الكتلة الإسلامية المهم، والمتعدد في الواقع الفلسطيني، كما تؤسس هذه الدراسة لقياس مدى تأثير الأنشطة الطلابية المختلفة - بأوزاها التي استطلعها الباحث- على قناعات الطلبة وسلوكهم.

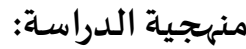

اتَّبعت الدراسة المنهج الاستقرائي الاستطلاعي؛ حيث اعتمدت الدراسة المنهج الاستقرائي في جمع البيانات والمعلومات

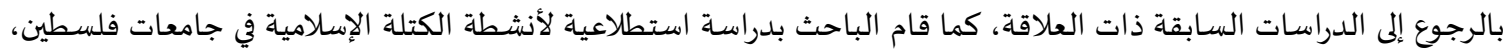

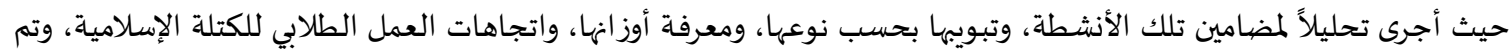

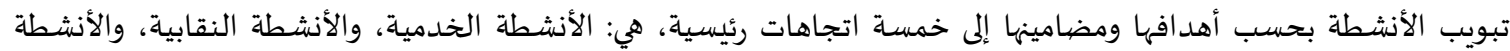
الدينية ، والأنشطة الوطنية، ثم الأنشطة الثقافية. 


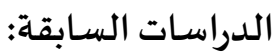

اهتمت العديد من الدراسات والأبحاث والمقالات بالحركة الطلابية الفلسطينية، خصوصاً في جوانب تأثيرها المختلف

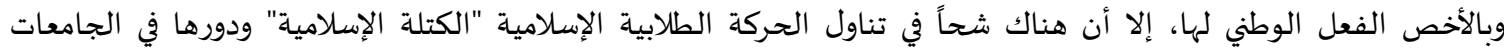

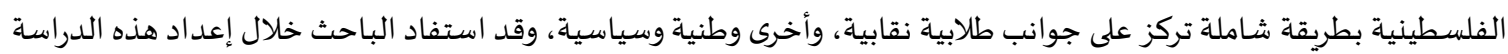

من بعض تلك الأبحاث والكتب والمقالات المتعلقة بالحركات الطلابية الفلسطينية وأنشطتها، ومنها:

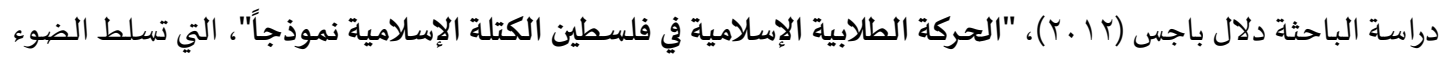

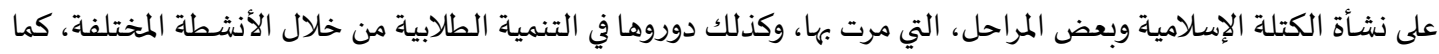

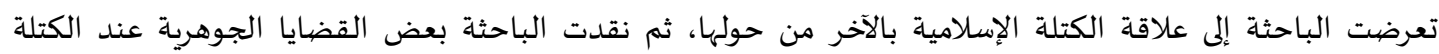
الإسلامية؛ كالخطاب، والنظرة إلى المرأة، وغيرها.

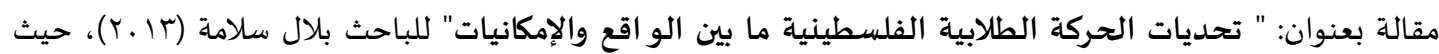

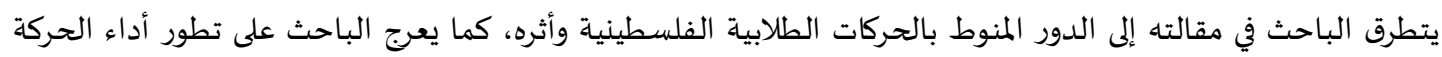
الطلابية الفلسطينية والعوامل التي أثرت فهها، خصوصاً اتفاقية أسلو، وتعرض الورقة البحثية محاولة لاستقصياء واقع

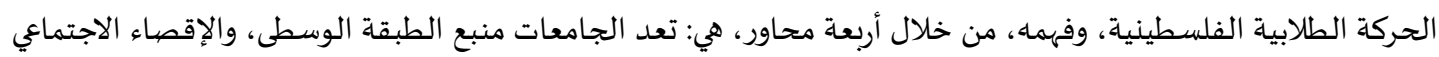
والتسلط السياسي، والتفرد السياسي والاقتصادي التي تمارسه السلطة، ثم استعراض نموذج جامعة بيرزيت في العمل الطلابي كنموذج متميز وناجح. ورقة بحثية بعنوان دور الأنشطة اللامنهجية في تعزيز الولاء لدى طلبة الجية الجامعات في محافظة غزة "دراسة ميدانية" للباحث

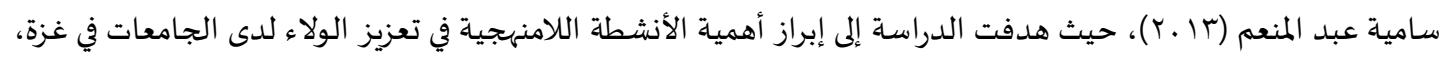

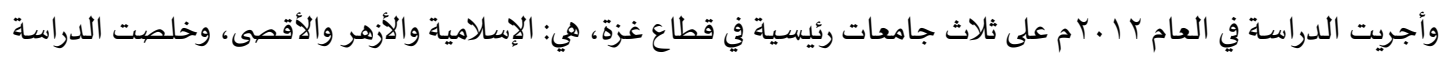

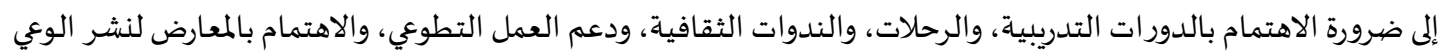
الثقافي والعلمي.

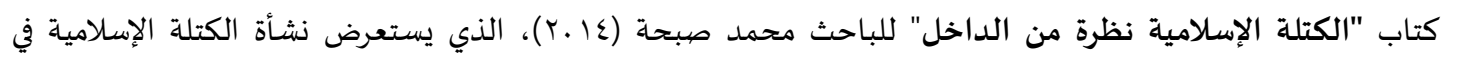

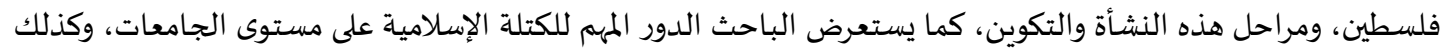

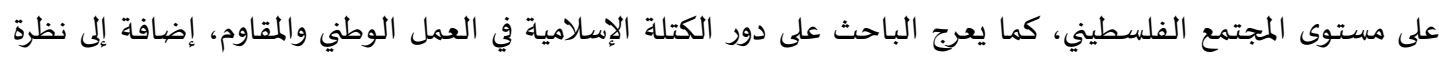
داخلية للكتلة الإسلامية، وهيكل عملها وآليات اتخاذ القرار فيها.

\section{المبحث الأول: النشأة والتعربف}

مع افتتاح الجامعات الفلسطينية بدأ التيار الإسلامي (الإخوان المسلمون) بالحراك الطلابي في تلك الجامعات، ولم تكن نشأة وانطلاقة الحركة الطلابية الإسلامية في الجامعات الفلسطينية عفوية، بل إن هناك عدة عوامل مهمة ساعدت على تكوين هذا

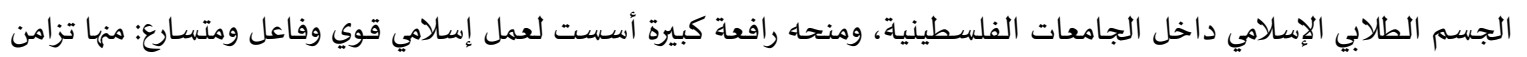

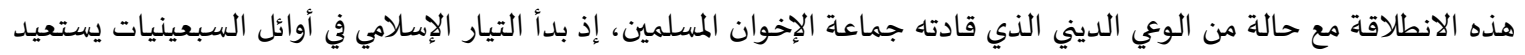

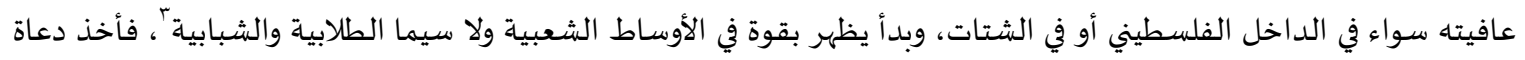

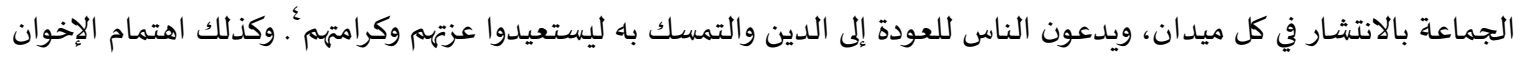

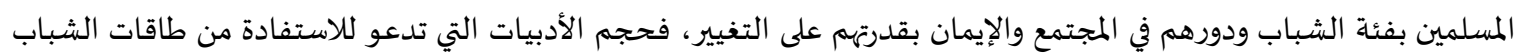

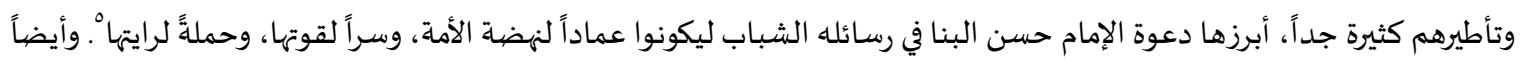

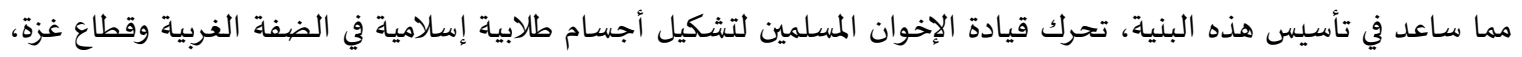
كالدكتور إبراهيم المقادمة وعبد العزيز الرنتيسي في الجامعة الإسلامية في قطاع غزة، وفضل فيل حمدان وحامد البيتاوي وإبراهيم أبو

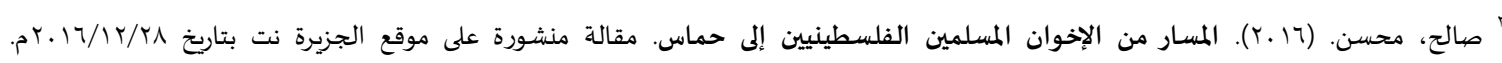
.http://www.aljazeera.net

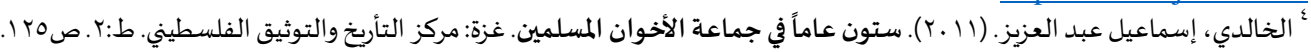

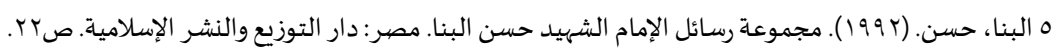


سالم في الضفة الغربية' . ومنها أيضاً، تأثر الطلبة الفلسطينيين المقيمين في الخارج وخصوصاً في مصر والأردن بتجربة الحركة الطلابية الإسلامية في تلك الدولتين، ونقلها للداخل الفلسطيني من خلال الشباب الفلسطينيين الذين درسوا في جامعات البلدين في سنوات الفيات

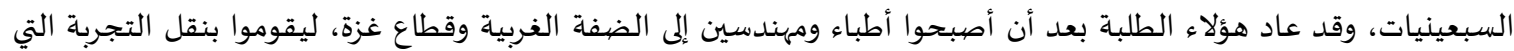
عايشوها هناك ل. ولا ننسى الحاجة الماسة لوجود تيار إسلامي داخل الجامعات يدعو للفكر الإسلامي والرؤية الإسلامية تجاه القضايا

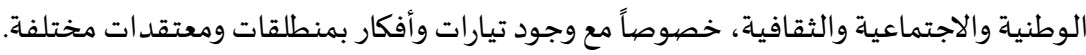

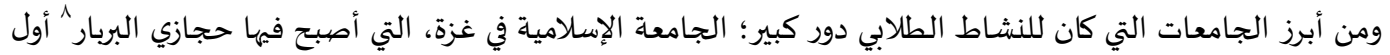

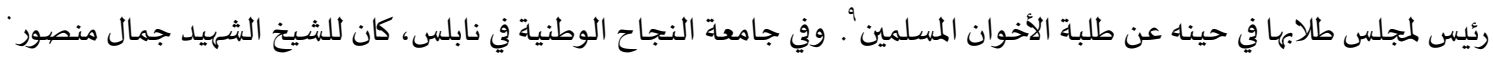

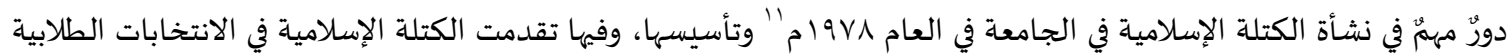

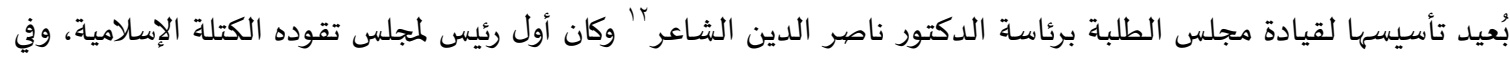
جامعة بيرزيت بدأ اسم الكتلة الإسلامية بالظهور في الجامعة بوصفه تجمعاً طلابياً إسلامياً مع بدايات العام 9NV على يد مجموعة من الطلبة الإسلاميين على رأسهه عبد الحليم الأشقر با مؤسس الكتلة في جامعة بيرزيت، ومحسن أبو عيطة وغيرهما، حيث انخرطت الكتلة الإسلامية في العمل الطلابي وحققت فوزاً في النادي الأدبي في مئي

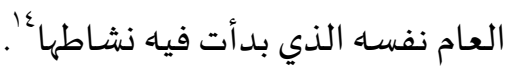
وتعرف الكتلة الإسلامية نفسها اليوم - بعد أكثر من أربعين عاماً من انطلاقتها- بحسب ما جاء على موقعها الرسمي بأنها:

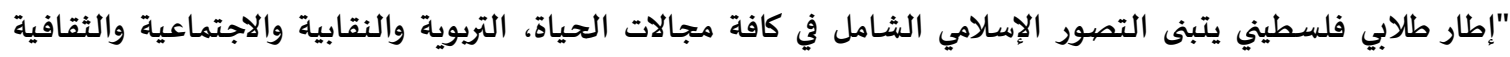

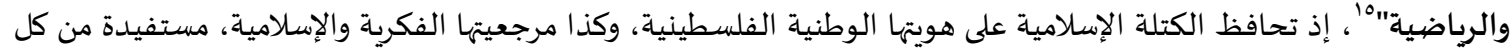
الوسائل والأدوات لتحقيق أهد افها المختلفة.

المبحث الثاني: مبررات وجود الحركة الطلابية الإسلامية في الجامعات الفلسطينية لم تخل الجامعات الفلسطينية منذ نشأتها من الأطر الطلابية المختلفة، وخصوصاً الأطر الطلابية التي تتبع الفصائل،

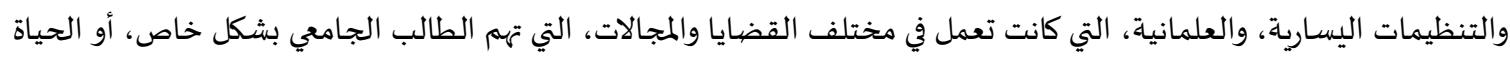
المجتمعية بشكل عام، إلا أن نشأة القطاع الطلابي للحركة الإسلامية أو ما يعرف بـ "الكتلة الإسلامية" بشكل رسمي مع هاية السبعينات شكل إضافة حقيقية في بعض القضايا، ونقلة نوعية في الأداء والإبداع.

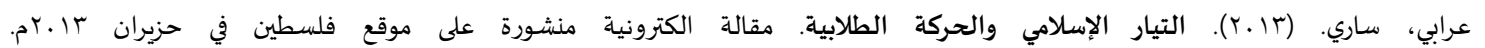
.http://palestine.assafir.com

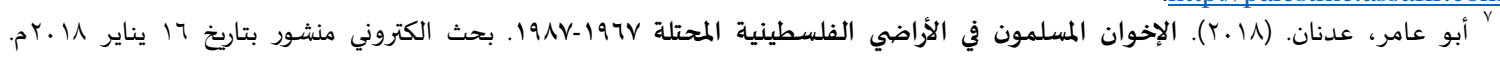
http://adnanabuamer.com ^حجازي البربار: أحد كوادر الإخوان المسلمين في فترة نهاية السبعينات، وأول رئيس مجلس لطلبة الجامعة الإسلامية بغزة.

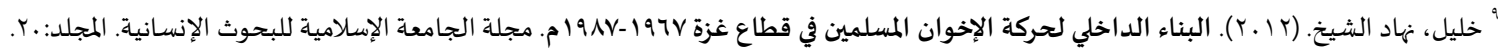

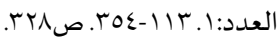

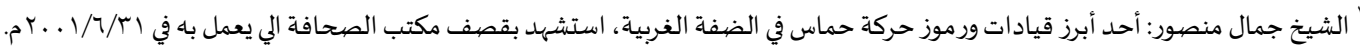

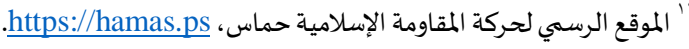
"' باجس، دلال. (r ا ـr). الحركة الطلابية الإسلامية في فلسطين الكتلة الإسلامية نموذجاً. فلسطين: مواطن، المؤسسـة الفلسطينية لدراسـة الديمقراطية، صזr. ناصر الدين الشاعر: أول رئيس مجلس طلبة عن الكتلة الإسلامية في جامعة النجاح، وزير التربية والتعليم في الحكومة الفلسطينية العاشرة، محاضر في كلية الشريعة في جامعة النجاح الوطنية. †' عبد الحليم الأشقر : أحد مؤسسي الكتلة الإسلامية في جامعة بيرزيت، حاصل على شهادة الكتوراة في إدارة الأعمال ويعمل بروفيسوراً في العديد من الجامعات الأمريكية، اعتقلته السلطات الأمريكية عدة مرات بتهمة الانتماء والمساعدة بتمويل حركة حماس.

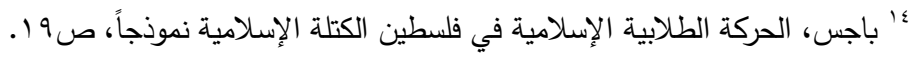

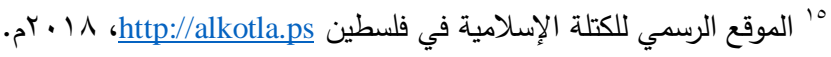


وعند النظر في البيئة، التي رافقت نشأة الكتلة الإسلامية في الجامعات الفلسطينية، نجد أن هناك عدة مبررات لهذا الوجود، يمكن حصرها وقراءهها، كما أن هناك احتياجات ومتطلبات - متعلقة بالحياة الجامعية والاجتماعية- جاءت الكتلة الإسلامية

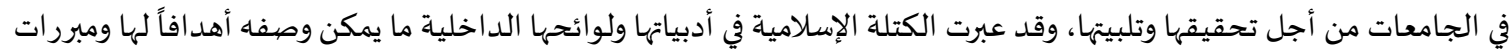
لوجودها، وهي تتركز في القضيايا الآتية:

المطلب الأول: الوظيفة الدينية والدعوية تعد الدعوة إلى دين الله تعالى وتذكير الناس باه من أهم المبررات التي وجدت من أجلها الكتلة الإسلامية، وتنسجم هذه

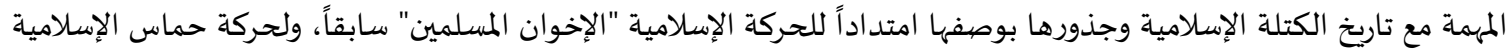

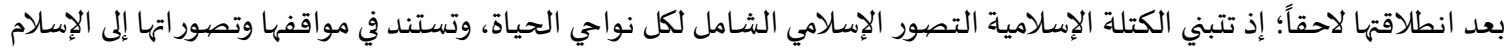

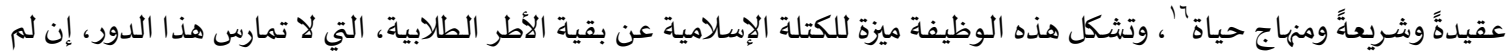
تمارس ما هو ضده ونقيضاه.

وقد كان للكتلة الإسلامية دورّ كبيوّ في مواجهة الأفكار اليسارية والعلمانية داخل الجامعات، وناضل نشطاء الكتلة نضالاً مستميتاً من أجل الحفاظ على الهوية الإسلامية لطلبة الجامعات، من خلال دعوتهم إلى الالتزام بتعاليم الدين الإسلامي الحنيف

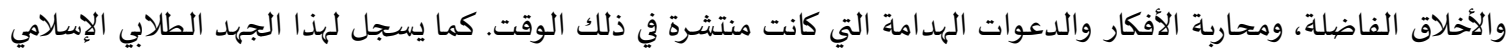
المنظم عبر سنوات عمله الثلاثين أنه استطاع الحفاظ على صوت الدين، والداف والأخلاق الحسنة، والقيم الإيجابية داخل الجامعات، وأعاد

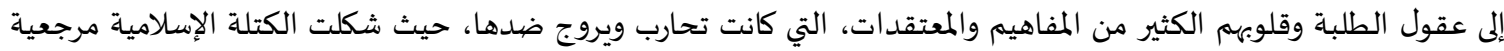
قيمية وأخلاقية'”

المطلب الثاني: الدور الوطني المقاوم إن وجود الاحتلال الصهيوني في فلسطين كان سبباً حتمياً ومنطقياً لوجود الكيانات والتنظيمات الفلسطينية المقاومة على الماوم

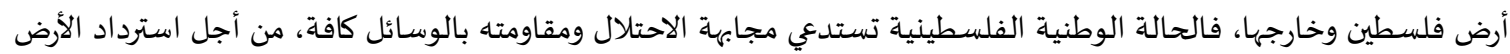
التي سلبها الاحتلال وشرد أهلها منها. لقد أضافت مشاركة الكتلة الإسلامية - ذراع الإخوان المسلمين في حينه- البعد "الإسلامي" للصبراع مع الاحتلال الصهيوني، وأعادت إلى الأذهان أنّ النصر والتحرير مرتبطان بالعودة إلى الله، والاعتصام بدينه وهدياه، وساعد في انتشار هذه القناعات الهزائم التي منيت بها الجيوش العربية في حروب ثلاثة بعد احتلال فلسطين في العام هعوأم، التي مثلت نتيجتها علامة فارقة في السجال

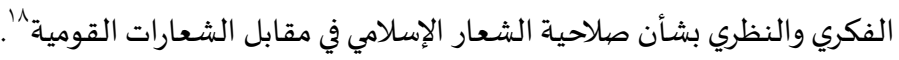
تؤمن الحركة الإسلامية "الإخوان المسلمين" منذ نشأتها بضرورة مقاومة الاحتلال الصهيوني في فلسطين وطرده منها، حيث الصيثان كانت القضية الفلسطينية أهم الأولويات لدى الجماعة، ومما قاله مؤسس الجماعة الجمسائ حسن البنا: "وجوب الجهاد لتحرير فلسطين

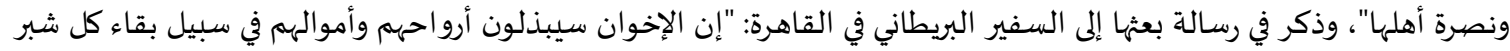

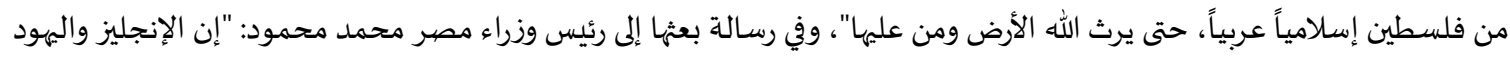

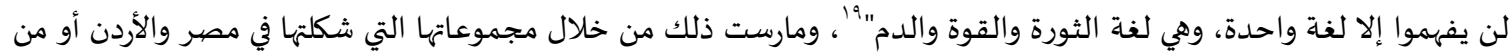
خلال نشاطها داخل فلسطين عبر فرع الإخوان هناك. وقد جاء انخراط الكتل الإسلامية في مقاومة الاحتلال ومواجهته اعتقاداً منها بهذه الثقافة والتربية، وامتداداً لهذا التارئان هاريخ، واعتقاداً من قياداتها بالضرورة الملحة لمشاركة الإسلاميين في العمل الوطني الفلسطيني، ورصيد الكتهنيد الكتلة الإسلامية بكوادرها ونشطاؤها كبير جداً، "وإن هذا الرصيد الكبير والمؤثر كان من أهم دوافع استهداف الاحتلال والسلطة لها على حد سواء، ولغاية تحجيم تأثير

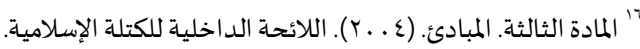

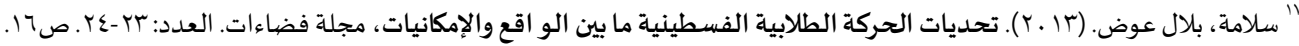

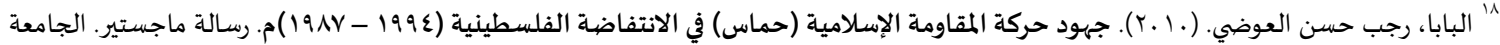

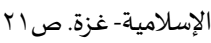

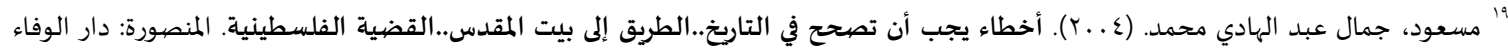

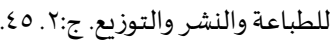
المجلة الدولية للدراسات الإسلامية المتخصصية _ المجلدب، العددr - 19 
الكتلة في البيئة الجامعية وعزلها عن قطاع الطلبة، أي قطاع الشباب، وهو القطاع الأهم فلسطينياً وخصوصاً على صعيد صنع

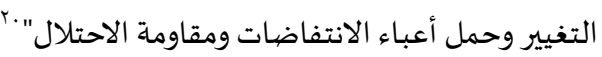

المطلب الثالث: الدور السياسي

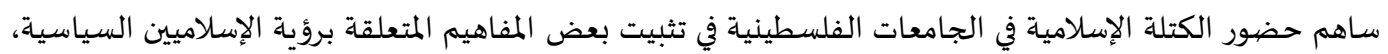

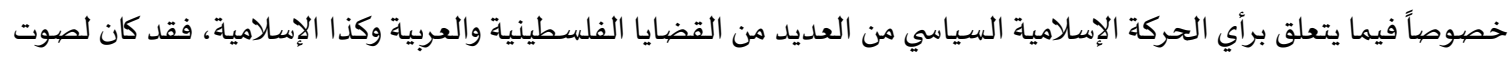

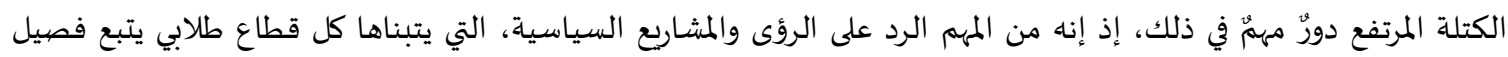

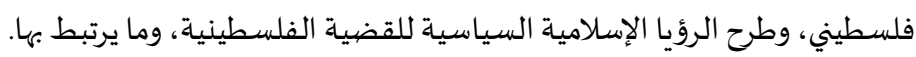

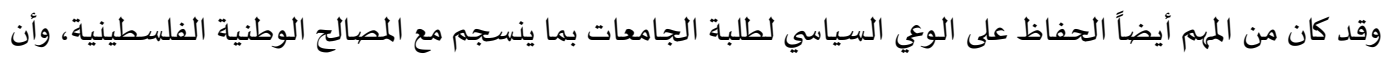

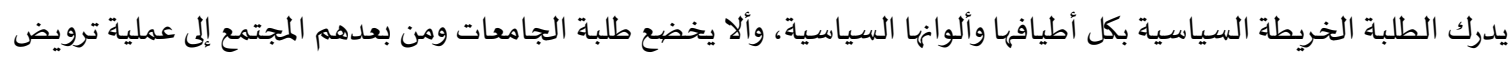

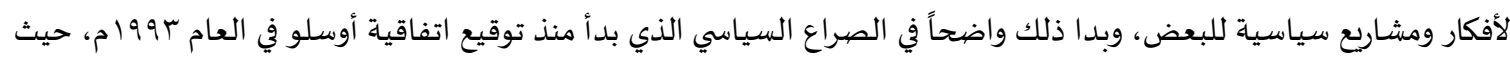

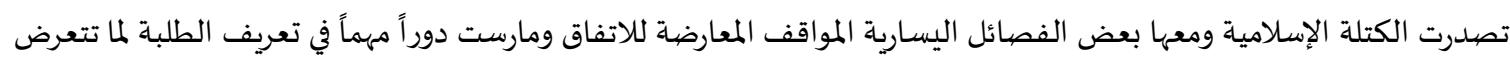

له القضية الفلسطينية مشكلة وعياً سياسياً تجاهها.

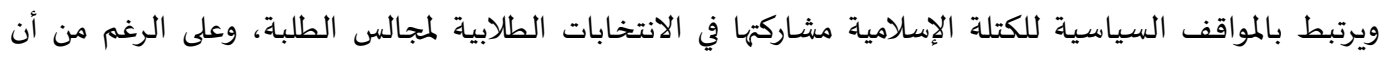

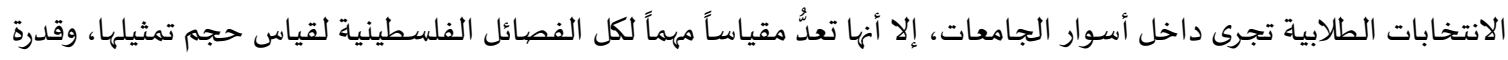

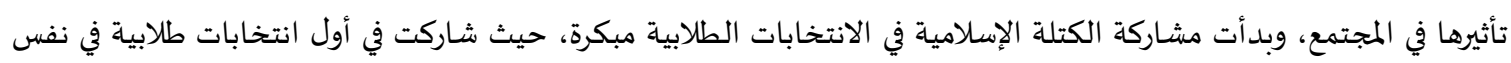

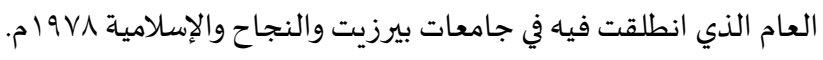

$$
\text { المطلب الر ابع: الدور النقابي }
$$

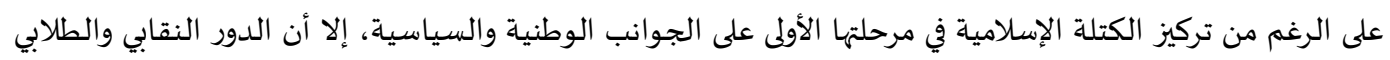

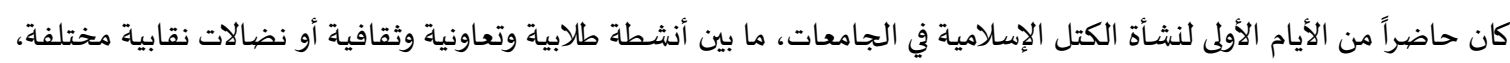

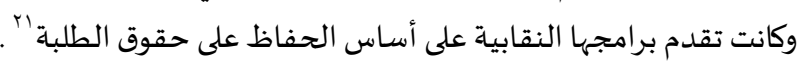

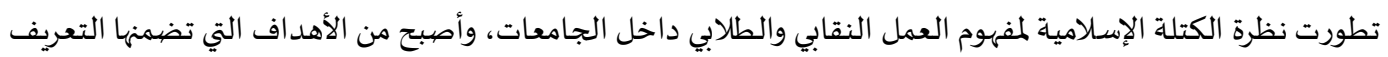

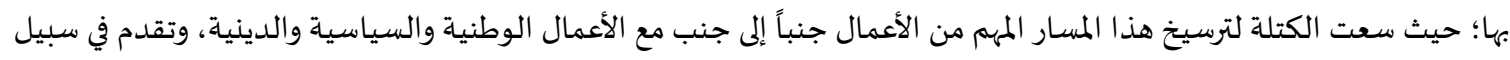

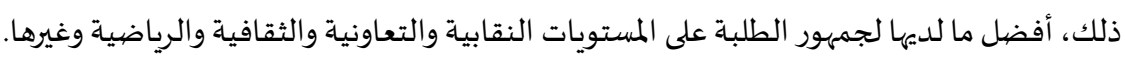

المبحث الثالث: محطات مهمة في تاريخ الكتلة الإسلامية

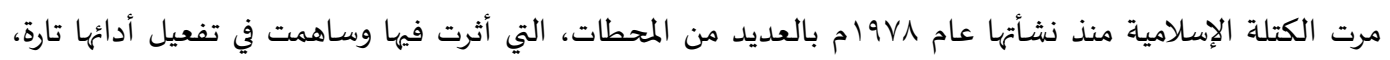

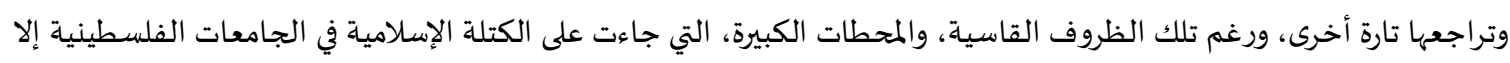

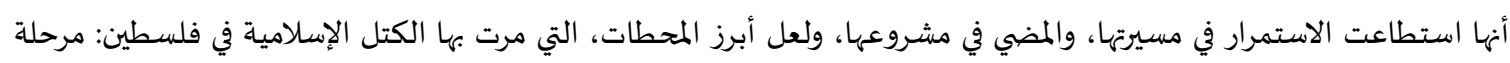

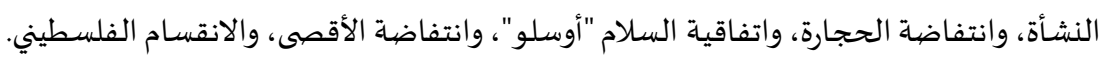

المطلب الأول: النشأة 19V1 م ومرحلة الصراعات الفكرية والسياسية

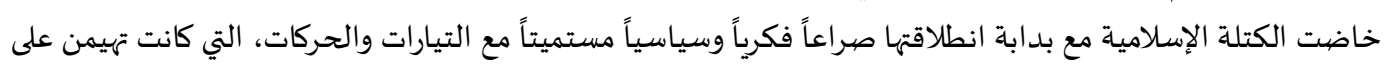

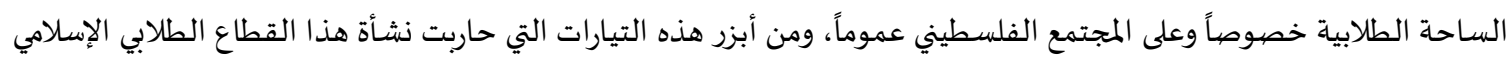

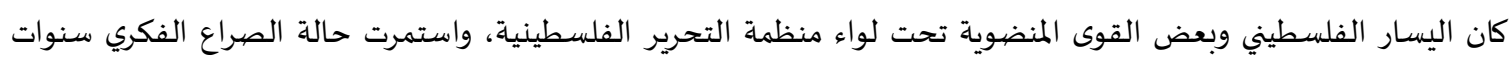

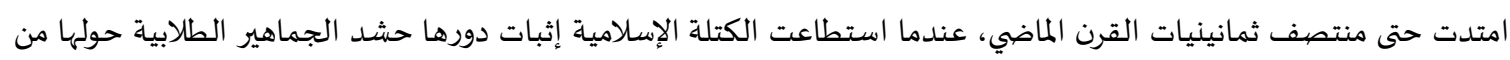

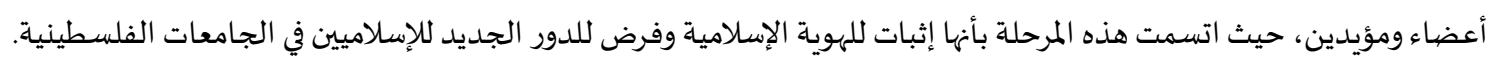

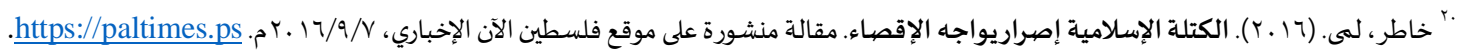

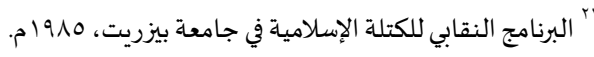


شكَّل هذا الصراع بعداً فكرياً متعلقاً بمحاربة وجود كتلة طلابية تحمل الفكر الديني وتدعو للالتزام بالتعاليم والأخلاق

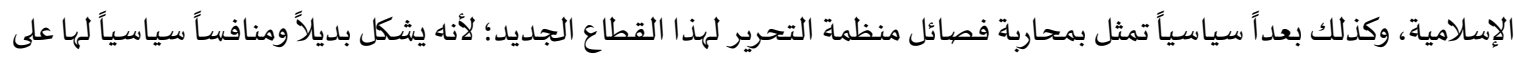
الساحة الطلابية، وقد امتد هذا الصراع والتنافس بين التيار الإسلامي الوليد "الكتلة الإسلامية" وبين معارضيه خصيوصياً اليسار الفلسطيني - الذي كان يشهد مرحلة انتعاش وصعود- ليشمل معظم ساحات الجامعات في الضفة الغربية وقطاع غزة كاند كان من أبرزها

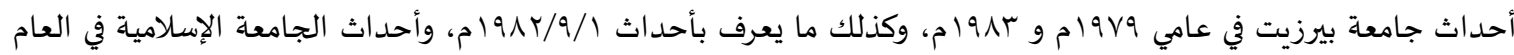
rr

المطلب الثاني: انطلاقة انتفاضة الحجارة l91V م و إثبات الذات

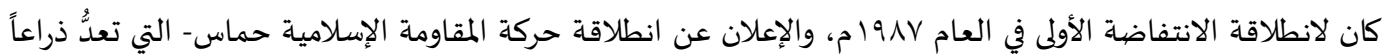

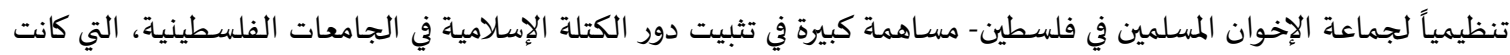

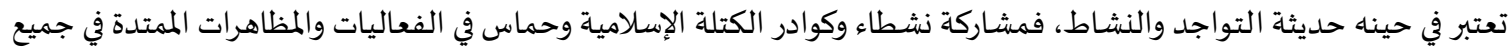

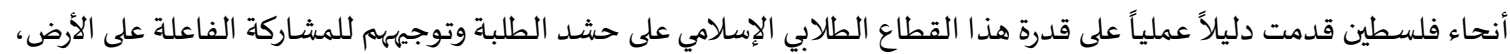

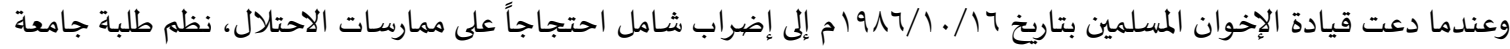

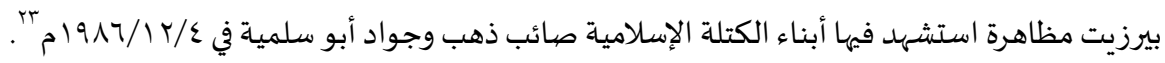

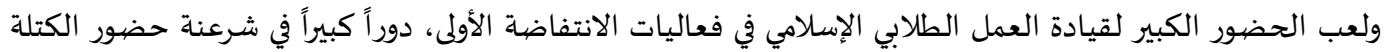

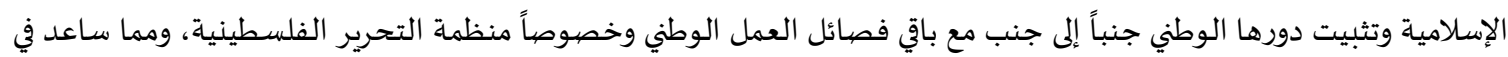

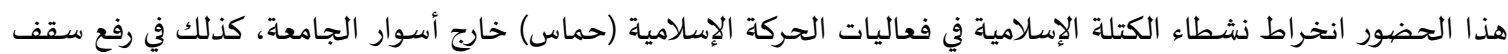

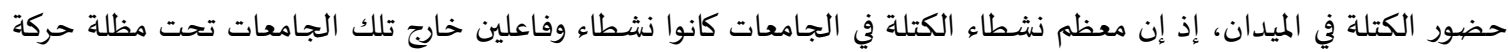
حماس.

المطلب الثالث: اتفاقية أوسلو 999 ام ومرحلة الصعود بعد تسلم السلطة الفلسطينية لمناطق (أ) في الضفة الغربية وقطاع غزة بموجب اتفودة الفاق أوسلو الذي وقع في العام بو 199 م، بدأت السلطة الفلسطينية بفرض حكمها على المناطق التي سيطرت عليها، الأمر الذي انعكس على خصهمها السياسي (حركة حماس)

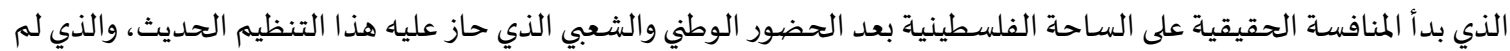
يمر على تأسيسه سوى بضعة سنوات. وعلى الرغم من حجم الضغط والملاحقة الذي مارسته أجهزة أمن السلطة طوال فترة سيطرتها الفعلية على مناطق (أ)، حتى

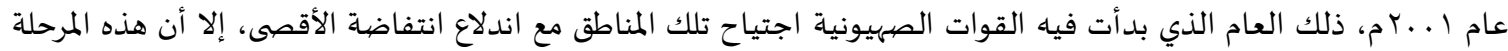

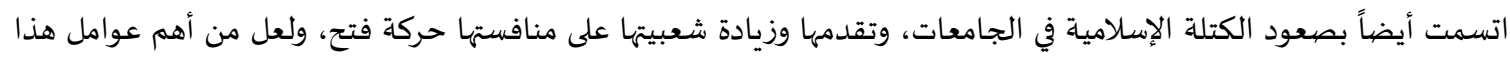

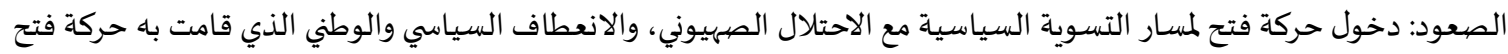

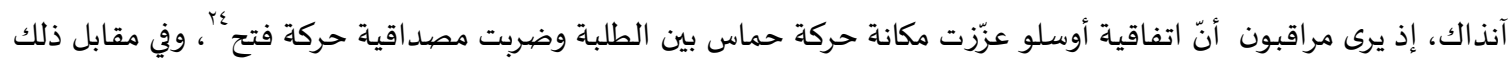

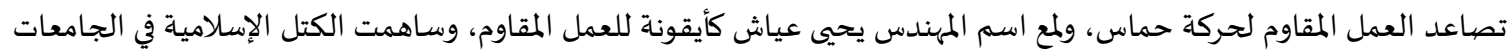

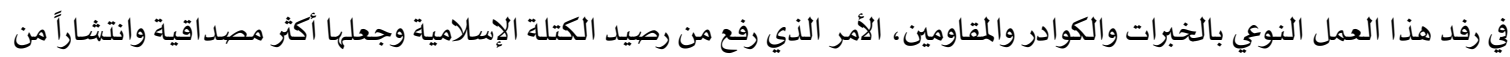
منافستها حركة فتح.

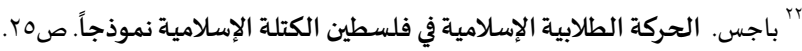

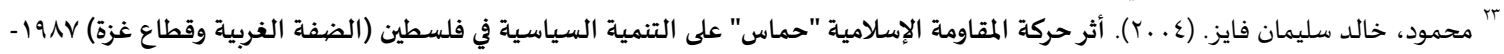

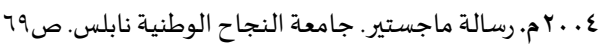

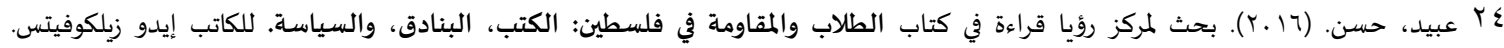




$$
\text { المطلب الر ابع: انتفاضة الأقصى ... . ب موالعمل المقاوم }
$$

كان للحركة الطلابية الفلسطينية دور وأثرُ كبيران في انتفاضية الأقصى، حيث دفعت الحركات الحمات الطلابية بأبنائها وجمهور

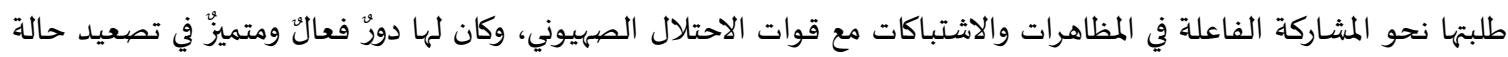
المواجهة مع الاحتلال، وتصدرت الحراكات الطلابية، وقدمت الشهداء والجرحى في تلك المواجهات.

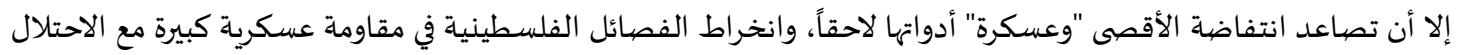

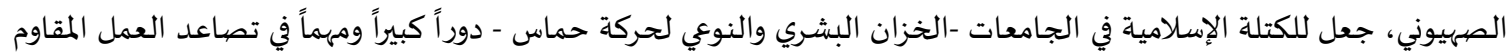

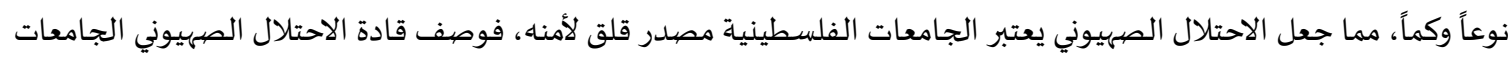
بأها "دفيئة المخربين"، وساهمت مشاركة الكتلة الإسلامية في انتفاضة الأقصى الثانية في جعلها تحت الاستهداف الصهيوني المتكرر

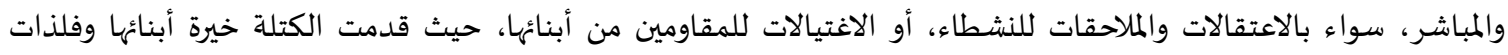

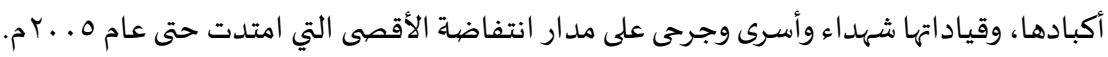

المطلب الخامس: الانقسام الفلسطيني V . . r م مرحلة التضييق والحظر

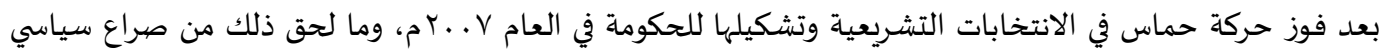

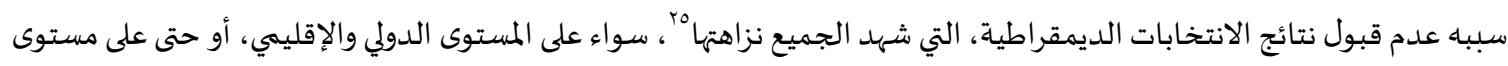

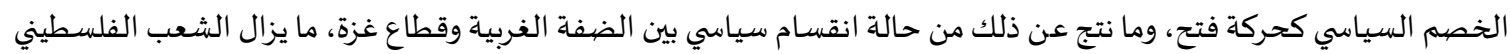
يعاني من تداعياتاه وآثاره حتى الآن.

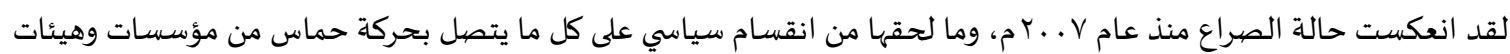

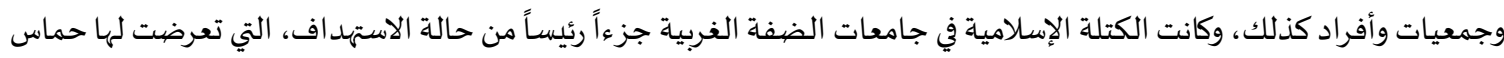
باعتبارها الذراع الطلابي لها؛ حيث تعرض قيادات وكوادر الكتلة في سنوات ما بعد الانقسام للملاحقات والاعتقالات الشديدة،

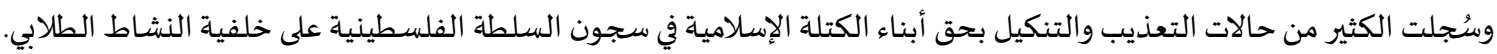
وصنفت السلطة الفلسطينية الكتلة الإسلامية في جامعات الضفة ضيمن قائمة الحظر على العمل كما حصل مع الحسل الحركة

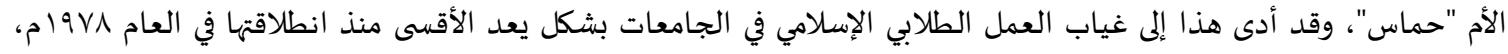

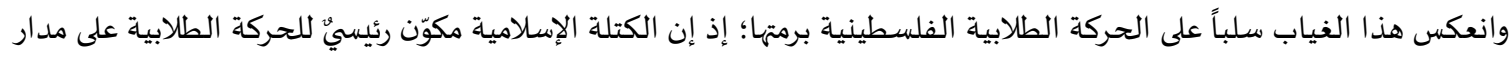

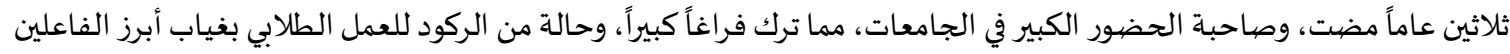
والمنافسين.

\section{المبحث الر ابع: اتجاهات عمل الكتلة الإسلامية في الجامعات} ترفع الكتلة الإسلامية شعاراً قديماً تعتبره منهجاً لها في عملها، وهو "خدمة الطالب عبادة نتقرب بها إلى الله"، إذ تسوق إنهات

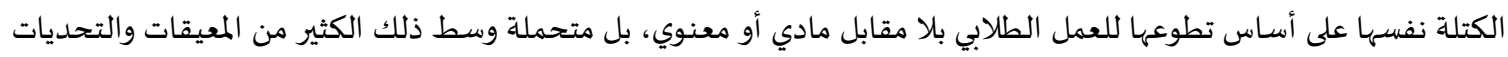

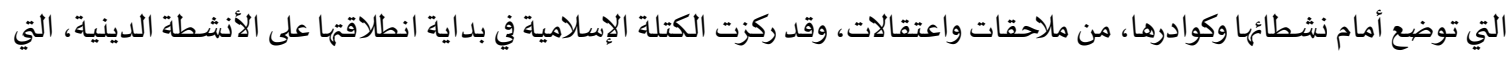

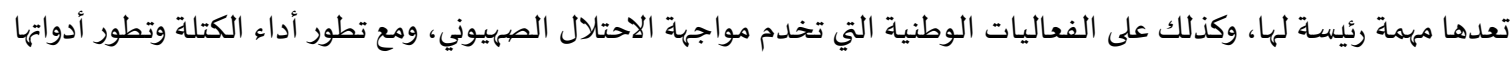

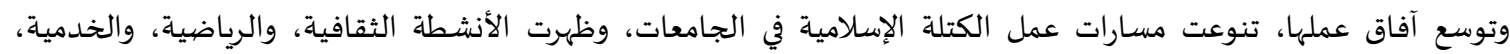

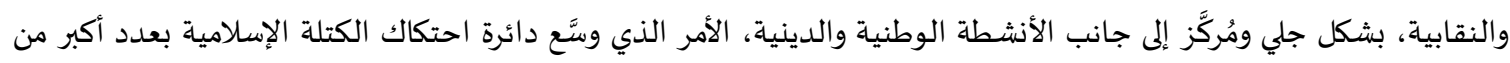

شرائح وطلبة الجامعات.

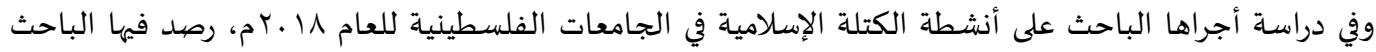
الأنشطة التي قامت بها الكتلة الإسلامية في جامعات الضفة الغربية وقطاع غزة، حيث قُسمت الأنشطة والفعاليات تبعاً لهدفها

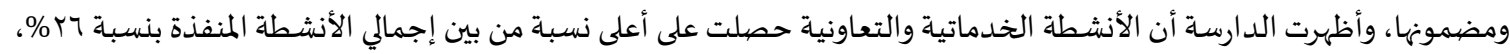

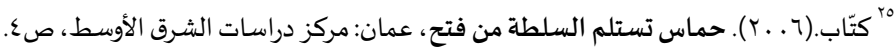


بينما تلتها الأنشطة النقابية والأكاديمية بنسبة 19\%، ثم جاءت الأنشطة الدينية والقيمية بنسبة \1\%، ثم الأنشطة الوطنية

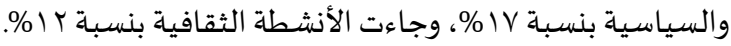

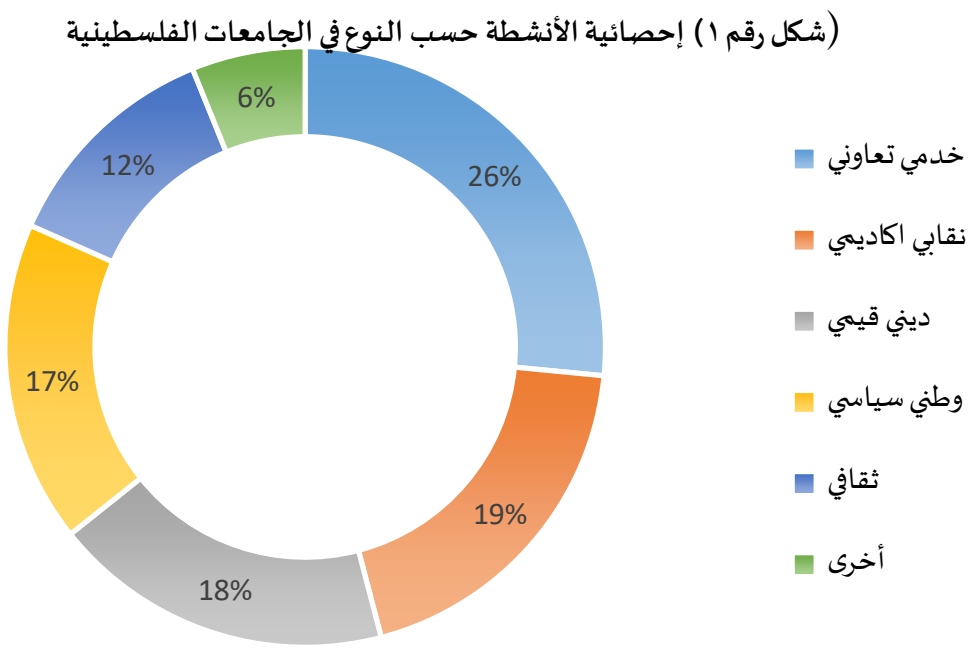

المطلب الأول: الأنشطة الدينية والقيمية

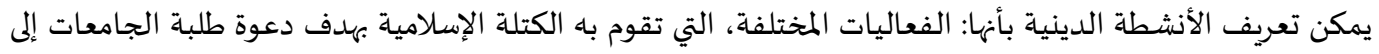

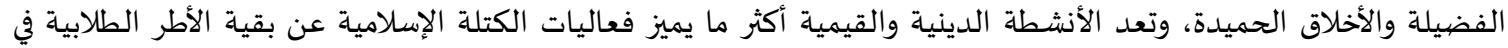

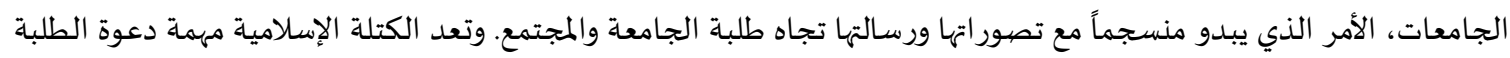

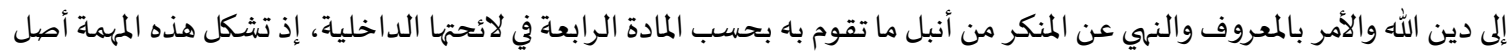

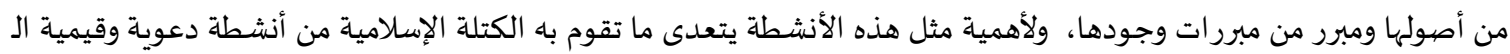

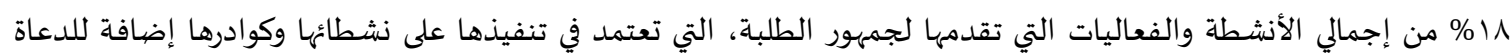
والمصلحين من داخل وخارج لجامعات. وساهم الحراك الدعوي للكتلة الإسلامية في الجامعات، في إيجاد منصاة عمل دعوي أشبه بالحاضنة القيمية، أثَّرت على مدار سنوات في فكر الطلبة وسلوكهم، وحافظ على الرمزيات الدينية والهوية الإسلامية في الجامعات، من خلال تشجيعها على الالتزام

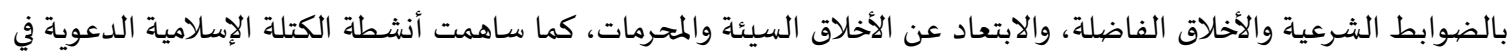
صناعاة طلبة متمرسين في فن الدعوة إلى الله تعالى، وقدرة عالية على مخاطبة عقول الناس والتأثير بهم، وتهدف الأنشطة الدينية التي

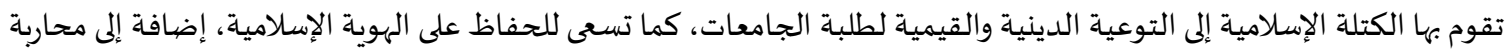
الأفكار والمشاريع الهد امة، وتنمية المهارات الدعوية والوعظية لدى القائمين على تلك الأنشطة.

المطلب الثاني: الأنشطة التعاونية والخدماتية

يقصد بالأنشطة الخدمية والتعاونية تلك التي تقدم الأطر الطلابية من خلالها للطلبة خدمات مجانية أو شبه مجانية تساعدهم في حياتهم الجامعية، كالخدمات التعليمية والترفيهية والمالية والمعيشية، وتعتمد الأنشطة الخدمية - كما بقية الأنشطة الطلابية- على مبدأ العمل التطوعي وخدمة الآخرين بلا مقابل مادي، وتتسع الفعاليات الخدماتية، التي تقوم بها الأطر الطلابية

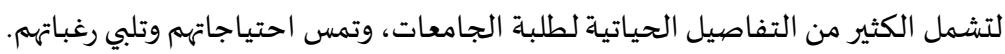

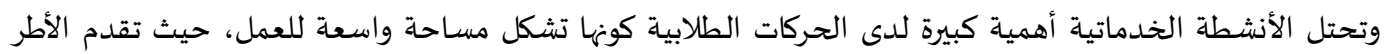
الطلابية خدماتها المتنوعة لطلبة الجامعات من أجل الوصول للطلبة وكسب ثقتهم، وكذلك يعد هذا النوع من الأنشطة من

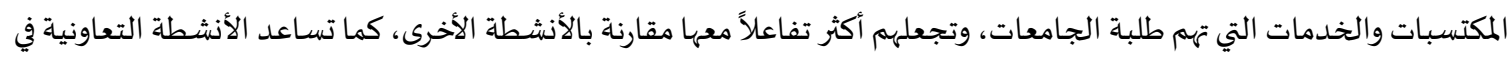

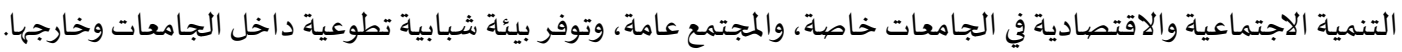


وعلى الرغم من أن بعضههم بَ يعد مثل هذه الأنشطة ثانوية وغير ضرورية، وقد تفسـد العمل الطلابي وتحيده عن مساره

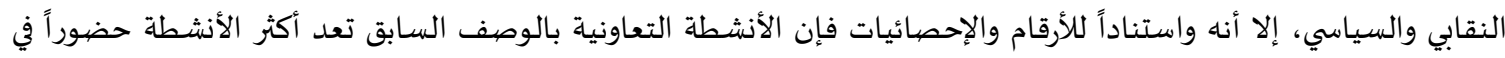

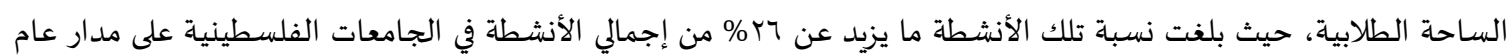
كامل، وهذا يدلل على أهمية تلك الأنشطة، ومدى تركيز الأطر الطلابية علهيها والاستفادة منها.

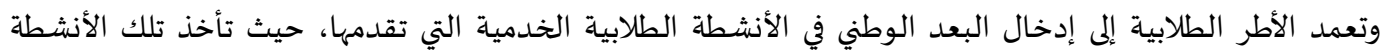

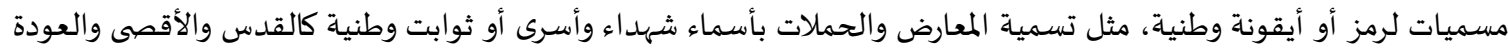

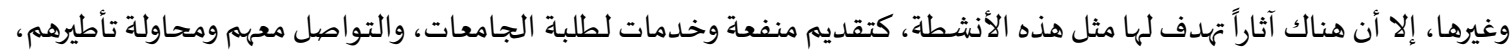
كما المساهمة في التنمية الاجتماعية والاقتصادية. المطلب الثالث: الأنشطة الأكاديمية والنقابية

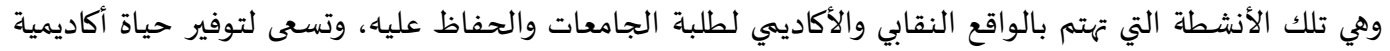

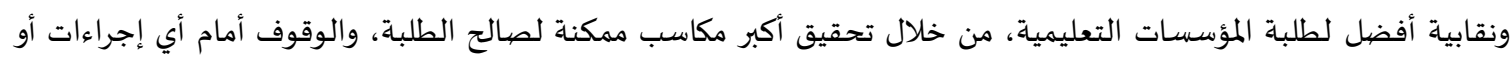
قرارات تمس حقوق الطلبة ومصالحهم المادية والمعنوية والتعليمية.

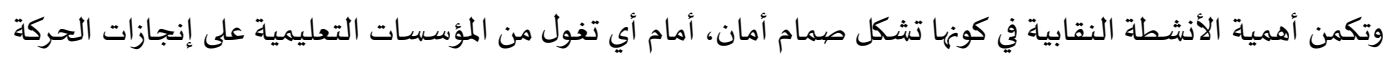

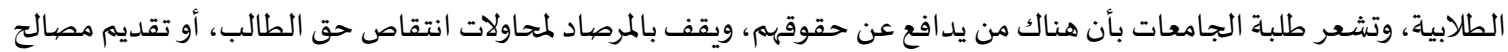

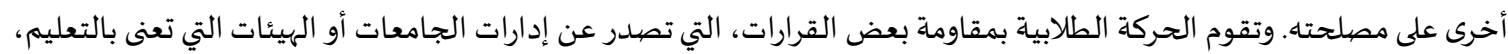

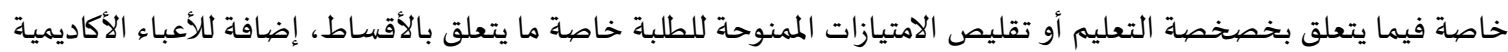

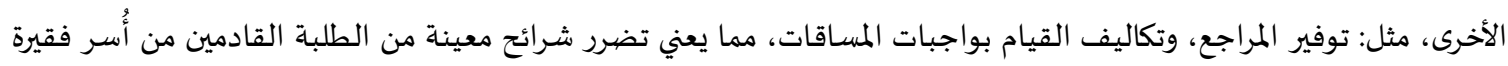

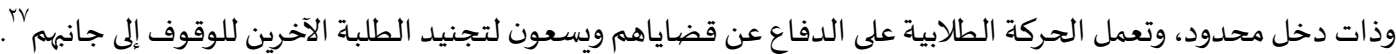

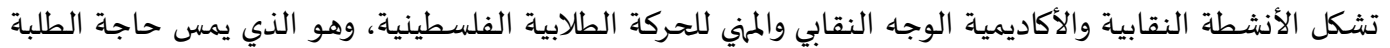

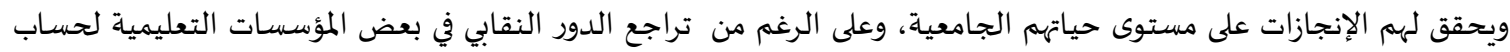

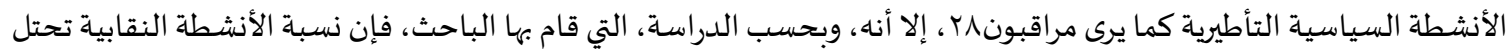

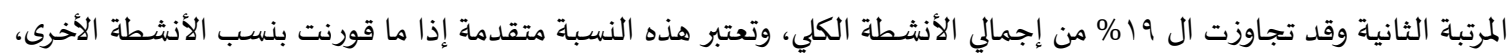
وتهدف هذه الأنشطة إلى الدفاع عن حقوق الطلبة ومواجهة قرارات الجامعات المجحفة بحق الطلبة، كما تسعى لتحسين الواقع التعليمي لطلبة الجامعات، وإعداد قيادات نقابية في المجتمع وتأهيلهم.

المطلب الر ابع: الأنشطة الوطنية والسياسية

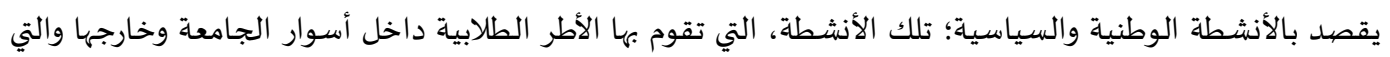
تركز في مضامينها وأدواتها على القضايا الوطنية والسياسية الفلسطينية، بهدف الحفاظ على الهوية الوطنية وتعزيز الانتماء والتضحية من أجل فلسطين، وتعميق الفهم السياسي في المسائل المتعلقة بالحالة الفلسطينية.

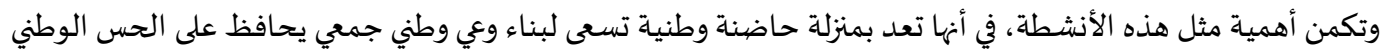

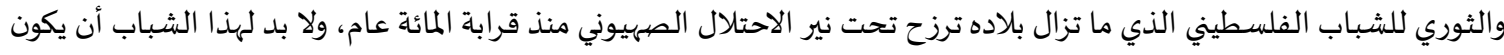

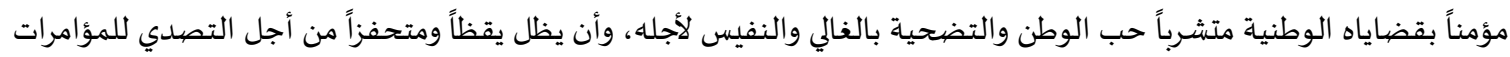
والتسويات التي تواجه القضية الفلسطينية، وأن يبقى طلبة الجامعات الدرع الحامي للقضية وصاحب الحضور التبادية الكبير في ميدان

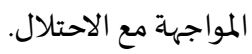

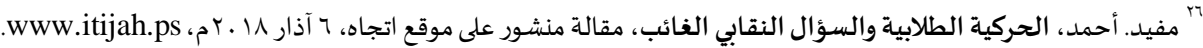

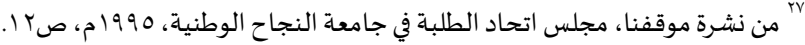

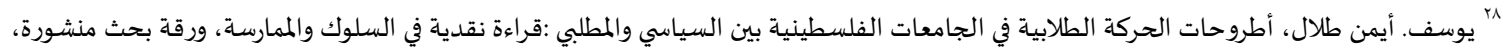

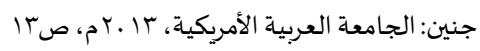


وبحسب الدراسة التي أجريت على رصد الأنشطة خلال العام VI أYم، فقد احتلت الأنشطة الطلابية المرتبة الرابعة في عدد الأشطة التي نفذتها الكتلة الإسلامية في جامعات الضفة الغربية وقطاع غزة، حيث نفذت قرابة IV IV، من إجمالي الأنشطة

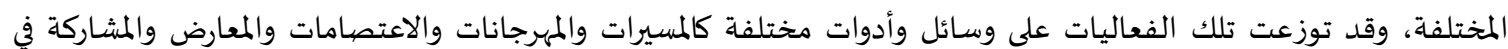
المواجهات المختلفة إضافة للجهد الإعلامي والتعبوي. وتهدف الأنشطة الوطنية والسياسية لتحقيق مجموعة من الأهداف كالحفاظ على الهوية الوطنية لطلبة الجمعات،

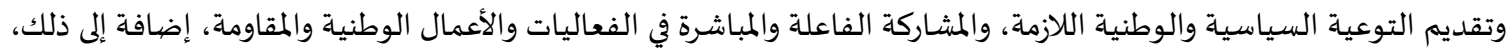
تأهيل قيادات وكوادر وطنية وسياسية.

المطلب الخامس: الأنشطة الثقافية

تهدف هذه الأنشطة إلى الارتقاء بالمستوى الثقافي لدى طلبة الجامعات، ومنحهم المعلومات والمهارات والخبرات في مجالات متعددة إنسانية وعلمية، من خلال العديد من الأنشطة الطلابية الميدانية والإلكترونية، ويتمثل النشاط الثقافي بعقد المحاضرات والندوات والدورات الثقافية والمسابقات العلمية والأدبية بين الأقسام المختلفة داخل إطار الجامعات وخارجها، وإتاحة الفرصية

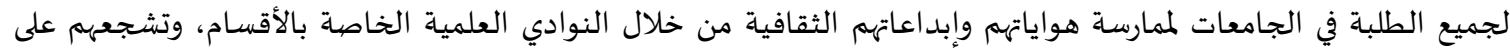

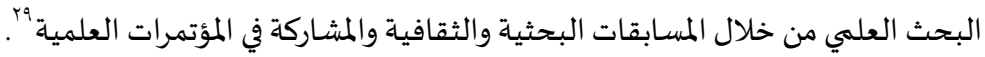
يعد الفعل الثقافي الطلابي الفلسطيني في الجامعات مدخل مهم لرؤية المشهد الثقافي الفلسطيني العام، وتعد الطاقة الطلابية مهمة جداً عند الحديث عن الوضع الثقافي الفلسطيني، وليس ذلك لمضامين الأنشطة الطلابية فحسب، بل لأن في التنظيم

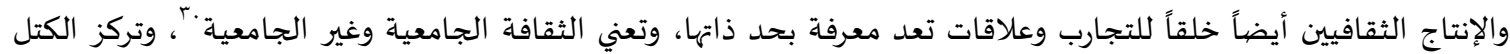

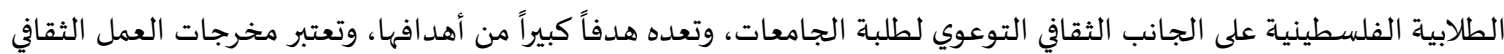
الطلابي إكمالاً لأي تقصير في الجانب الأكاديمي وإثراء لمعارف الطالب وإكسابه المهارات والقدرات، التي يحتاجها في حياته الجامعية

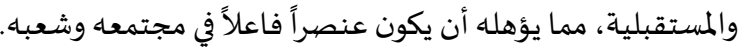

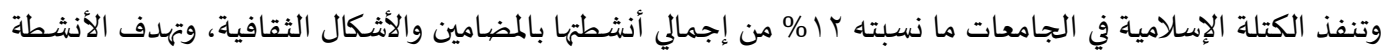
الثقافية، إجمالاً، للهوض بالمستوى الثقافي لدى طلبة الجامعات، والاستفادة من المهارات والطاقات الطلابية، إضافة إلى رفد المجتمع بكفاءات لديها ثقافة واطلاع ووعي، وتسهم بشكل مباشر في تثقيف المجتمع المحيط.

توصيات الدراسـة:

ا. توصي الدراسة الكُتَّاب والباحثين في الشأن الطلابي الفلسطيني، لإجراء مزيد من الدراسـات والأبحاث في دور الحركة الطلابية الإسلامية وأثر أنشطتها في طلبة الجامعات. r. توصي الدراسة القائمين على الأنشطة الطلابية بضرورة عمل تقييم دوري ومستمر للأنشطة الطلابية المختلفة من حيث

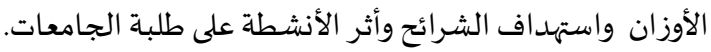
r. توصي الدراسـة الجامعات الفلسطينية لتوفير برامج تدريبية لقادة ونشطاء العمل الطلابي من أجل تدريبهم على التخطيط، والتنفيذ، والتقييم للأنشطة الطلابية. ع. توصي الدراسة بضرورة توفير أجواء آمنة للطلبة القائمين على الأنشطة الطلبة، وعدم ملاحقهم من قبل الجهات الأمنية داخل وخارج أسوار الجامعات الفلسطينية.

الخاتمة:

قدمت هذه الورقة تعريفاً للحركة الطلابية الإسلامية في فلسطين، ومراحل نشأتها في الجامعات الفلسطينية بعد نشأهها

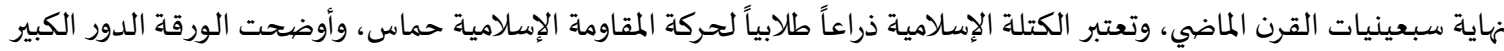

"rq عبدالمنعم. سامية عبد الله، دور الأنشطة اللامنهجية في تعزيز الولاء لدى طلبة الجامعات في محافظة غزة "دراسة ميدانية"، غزة: المؤتمر الدولي الأول

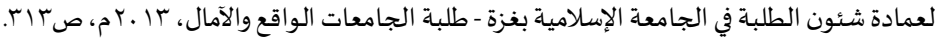

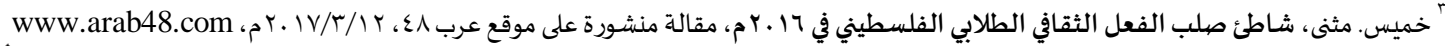


الذي تقوم باء الكتلة الإسلامية في المجتمع الفلسطيني على مستويات واتجاهات مختلفة أهمها السياسي والوطني، إضافة لوظيفة الكتلة الأسـاسية وهي الوظيفة الدينية، وعرضت الورقة المراحل التي مرت بها الكتلة الإسلامية منذ نشأتها حتى اليوم، التي كان أقساها

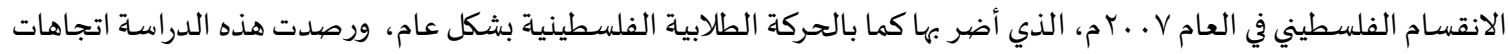
عمل الكتلة الإسلامية في الجامعات الفلسطينية، ووأزان تلك الأنشطة وأهدافها، كما أشارت الدراسـة إلى التأثير الحاصل لتلك باهلك الأنشطة على طلبة الجامعات وعلى المجتمع الفلسطيني بشكل عام.

المراجع:

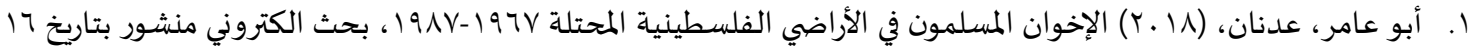

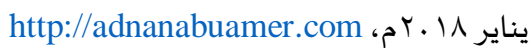

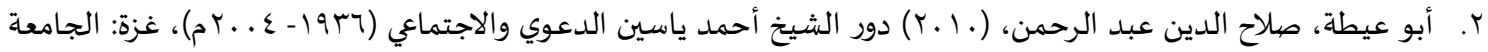
الإسلامية، بحث مقدم لنيل درجة الماجستير في التاريخ.

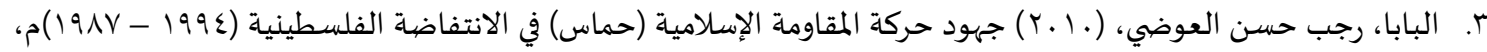
رسالة ماجستير، الجامعة الإسلامية- غزة. ع. باجس، دلال، (Y (Y) الحركة الطلابية الإسلامية في فلسطين الكتلة الإسلامية نموذجاً، فلسطين: مواطن، المؤسسـة الفلسطينية لدراسـة الديمقراطية.

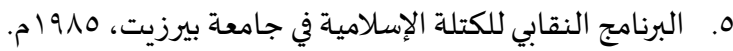

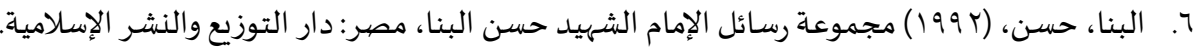

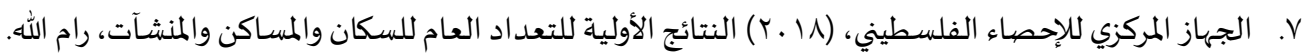

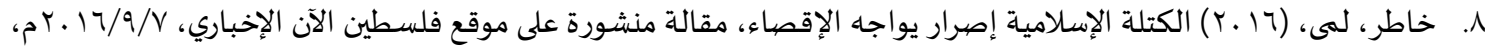
https://paltimes.ps

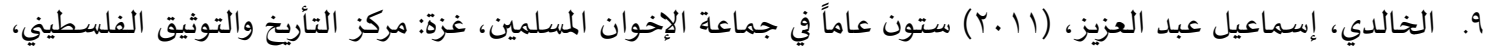
r:

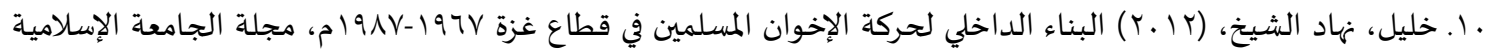

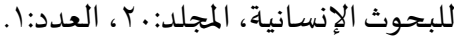

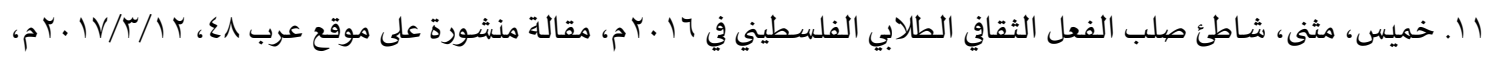
www.arab48.com

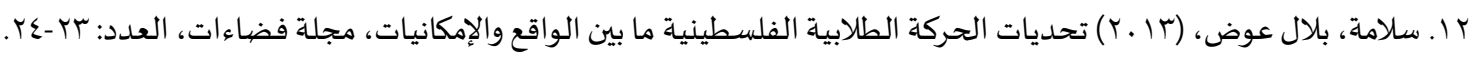
rا. صالح، محسن، (7 (Y) المسـار من الإخوان المسلمين الفلسطينيين إلى حماس، مقالة منشورة على موقع الجزيرة نت بتاريخ

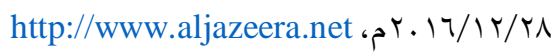
عا. عبدالمنعم، سامية عبد الله،(با ـr) دور الأنشطة اللامنهجية في تعزيز الولاء لدى طلبة الجامعات في محافظة غزة "دراسة ميدانية"، غزة: المؤتمر الدولي الأول لعمادة شئون الطلبة في الجامعة الإسلامية بغزة - طلبة الجامعات الواقع والآمال.

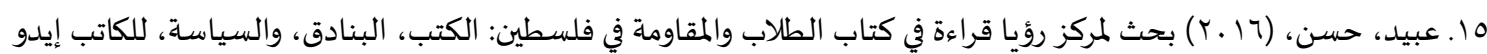

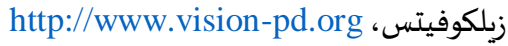

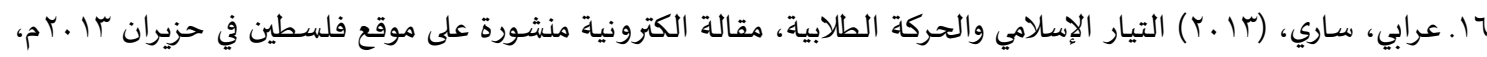
http://palestine.assafir.com

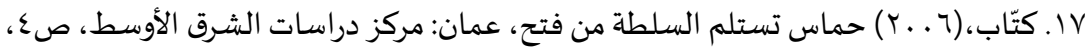

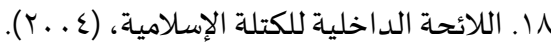
19. محمود، خالد سليمان فايز، (ع . . ) أثر حركة المقاومة الإسلامية "حماس" على التنمية السياسية في فلسطين (الضفة الغربية

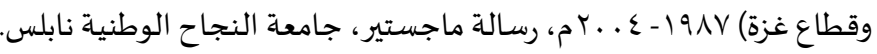

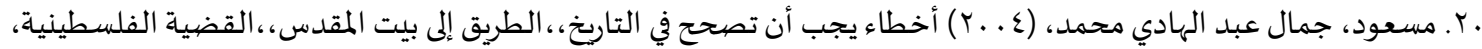

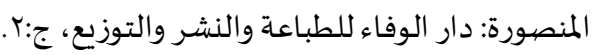




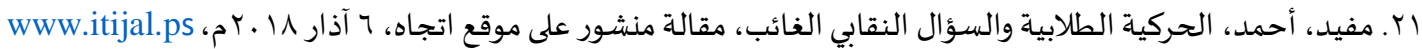

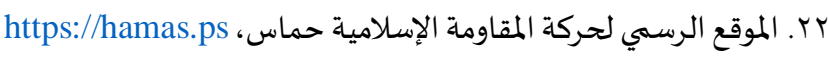

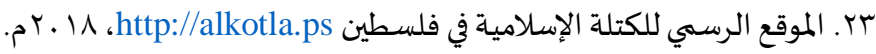
ع r. نشرة موقفنا، مجلس اتحاد الطلبة في جامعة النجاح الوطنية، 1990 م.

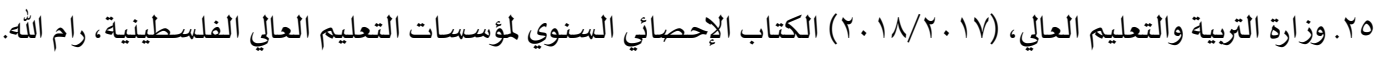
7r. يوسف، أيمن طلال، أطروحات الحركة الطلابية في الجامعات الفلسطينية بين السياسي والمطلبي :قراءة نقدية في السلوك

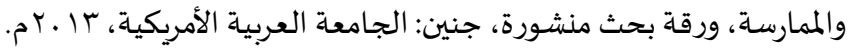




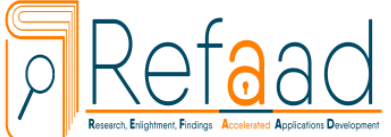

رفاد للدراسات والأبحاث

www.refaad.com

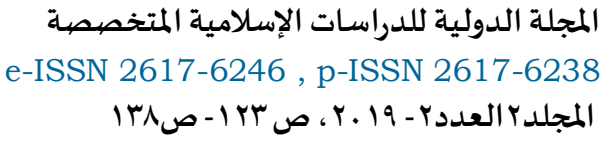

https://doi.org/DOI:10.31559/sis2019.2.2.1

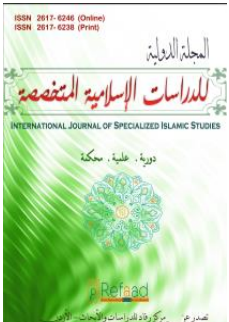

\title{
Islamic Student Movement In Palestinian- Origination And Role
}

\author{
Muath Ibrahim Ateeli \\ PhD student in Department of Dakwah and Leadership Studies- Faculty of Islamic Studies- \\ National University of Malaysia- Malaysia \\ muathateeli@gmail.com
}

\section{Muhamad Faisal Asha'ari}

Lecturer in Department of Dakwah and Leadership Studies- Faculty of Islamic Studies- National University of Malaysia- Malaysia

faisal@ukm.edu.my

\begin{abstract}
The Palestinian student movements, and since its establishment has played a significant role and considered as a powerful lever for national initiatives and students especially in the Palestinian universities. The influence of the Palestinian student movement has extended its scope from focusing purely on university students to reach to overall Palestinian community including the cultural, religious, national as well as politics aspects. The student movement represents a hippocampal shield for the Palestinian, the students. This paper sheds light on the emergence of the Islamic students sector in Palestine, which has shaped after the opening of Palestinian universities in 1978. The paper as well shows the justifications which Al-kotla alislamiya was established for such as; the religious, the national and the political function. The paper also shows five important stations through the history of Al-kotla i.e. (the establishment and identity affirmation phase, the first intifada phase, The Oslo agreements, the second intifada and the Palestinian division in 2007. In addition, this paper presents the workflows which al-kotla al-islamiya adopted to achieve their goals such as; the religious, the national, the services and the unions workflows and others.
\end{abstract}

Keywords: Islamic Student Movement, 1987 Intifada, Oslo Agreement, Al Aqsa Intifada, Palestinian Division.

\section{References:}

[1] 'bdạlmn 'm. Sạmyh 'bd Ạllh, Dwr Ạlạ̉nsḥth Ạllạmnhjyh Fy T'zyz Ạlwlạ' Ldy Ṭlbë Ạljạm ạt

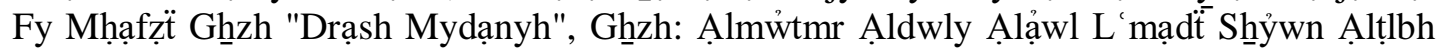
Fy Ạljạm h Ạlạslạmyh Bghzzh - Ṭlb̆̈ Ạljạm ạt Ạlwạq Wạlậmạl, (2013m).

[2] 'byd. Hụn, Bḥth Lmrkz Rw̉yạ Qrạ ‘̈ Fy Ktạb Ạlțlạb Wạlmqạwmh Fy Flsṭnn: Ạlktb, Ạlbnạdq, Wạlsyạsh, Llkạtb Á,ydw Zylkwfyts, (2016), http://www.vision-pd.org

[3] 'rạby. Sạry, Ạltyạr ẠlạSlạmy Wạlḥrkh Ạlțlạbyh, Mqạlh Ạlktrwnyh Mnsḥwrh 'la Mwq' Flsțn Fy Hzyrạn 2013m, http://palestine.assafir.com

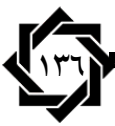


[4] Ạ̉bw 'ạmr. 'dnạn, Ạlạkhwwạn Ạlmslmwn Fy Ạlạ̉ạady Ạlflsțynyh Ạlmḥ̣tlh 1967-1987, Bḥth Ạlktrwny Mnshwwr Btạrykh 16 Ynạyr 2018m, http://adnanabuamer.com

[5] Ạ̉bw 'yṭh. Șlạh Ạldyn 'bd Ạlrḥmn, dwr Ạlshnykh Ạhmọm Yạsyn Ạld'wy Wạlạjtmạ'y (1936-

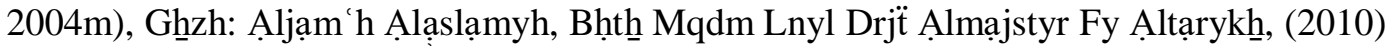

[6] Ạlbạbạ. Rjb Hsn Al'wḍ̂, Jhwd Hrkë Ạlmqạwmh Ạlạslạmyh (Ḥạs) Fy Ạlạntfạdh Ạlflsṭynyh (1994 - 1987M), Rsạlẗ Mạjstyr, Ạljạm'h Ạlạslạmyh- Ghzh, (2010)

[7] Ạlbnạ. Hụn, Mjmw‘đ̈ Rsạỷl Ạlạmạm Ạlsḥhyd Ḥsn Ạlbnạ, Mṣr: Dạr Ạltwzy` Wạlnsḥr Ạlạslạmyh, (1992)

[8] Ạlbrnạmj Ạlnqạby Llktlh Ạlạslạmyh Fy Jạm ‘̈ Byzryt, (1985m)

[9] Ạljhạz Ạlmrkzy Llạhṣạ' Ạlflsțyny, Ạlntạyj Ạlạ̉wlyh Llt'dạd Ạl'ạm Llskạn Wạlmsạkn Wạlmnshật, Rạm Ạllh, (2018)

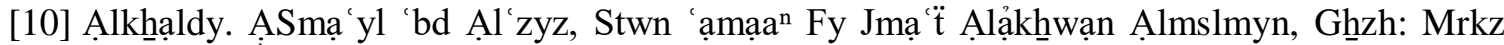
Ạltạ̉rykh Wạltwthyq Ạlflsțyny, Ṭ:2, (2011)

[11] Ạllạỷḥh Ạldạkhlyh Llktlh Ạlạslạmyh, (2004).

[12] Ạlmwq Ạlrsmy Lhrkë Ạlmqạwmh Ạlạslạmyh Ḥmạs, https://hamas.ps

[13] Ạlmwq`Ạlrsmy Llktlë Ạlạslạmyh Fy Flsțyn http://alkotla.ps, (2018m).

[14] Bạjs. Dlạl, Ạlḥrkh Ạlțlạbyh Ạlạslạmyh Fy Flsțyn Ạlktlh Ạlạslạmyh Nmwdḩjạaan, Flsțyn: Mwạṭn, Ạlmw̉ssh Ạlflsțynyh Ldrạsẗ Ạldymqrạtyh, (2012)

[15] Khạțr. Lma, Ạlktlh Ạlạslạmyh Ạsrạr Ywạjh ẠlạQQṣạ', Mqạlh Mnshọwrh 'la Mwq Flsțyn Ạlận ẠlạKhbạry, 7/9/2016m, https://paltimes.ps

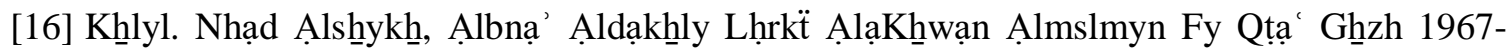
1987m, Mjlï Ạljạm’h Ạlạslạmyh Llbḥwth Ạlạnsạnyh, 20(1)(2012).

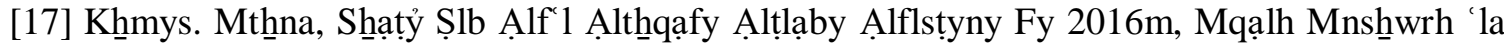
Mwq' 'rb 48, 12/3/2017m, www.arab48.com

[18] Ktạb, Ḥmạs Tstlm Ạlslṭh Mn Ftḥ, 'mạn: Mrkz Drạsạt Ạlsḥrq Ạlạ̉wsṭ, (2006),pp.4,

[19] Mfyd. Ạ̉hmd, Ạlḥ̣kyh Ạlțlạbyh Wạlswạal Ạlnqạby Ạlgḥạ̉b, Mqạlh Mnshọwr 'la Mwq Atjạh, 6 Ậhar 2018m, www.itijal.ps

[20] Mḥmwd, Khạald Slymạn Fạyz, Ạtḥr Ḥrkë Ạlmqạwmh Ạlạslạmyh "Ḥmạs" 'la Ạltnmyh Ạlsyạsyh Fy Flsțnn (Ạlḍfh Ạlghrrbyh Wqțạ' Ghzzh) 1987- 2004m, Rsạlẗ Mạjstyr, Jạm ‘̈ Ạlnjạh Ạlwțnyh Nạbls, (2004)

[21] Ms'wd. Jmạl 'bd Ạlhạdy Mḥmd, Ạ̉khțạ' Yjb Ạ̉n Tṣḥ̣ Fy Ạltạrykḥ,,Ạlttryq Ạla Byt Ạlmqds,,Ạlqḍ̂h Ạlflsțynyh, Ạlmnșwrh: Dạr Ạlwfạ’ Llṭbạ h Wạlnsh̆r Wạltwzy', J:2, (2004)

[22] Nsḥrẗ Mwqfnạ, Mjls Ạthạd Ạlṭlbh Fy Jạm đ̈ Ạlnjạh Ạlwṭnyh, (1995m).

[23] Șạlḥ. Mḥsn, Ạlmsạr Mn Ạlạkhnwạn Ạlmslmyn Ạlflsțynyyn Ạla Ḥmạs, Mqạlh Mnsḥwrh 'la Mwq' Aljzyrh Nt Btarykh 28/12/2016m, http://www.aljazeera.net 
[24] Slạmh. Blạl 'wḍ, Tḥdyạt Ạlḥrkh Ạlțlạbyh Ạlfsțynyh Mạ Byn Ạlwạq' Wạlạ Mkạnyạt, Mjlï Fḍạ’ ạt, Ạl'dd: 23-24(2013).

[25] Wzạrä Ạltrbyh Wạlt'lym Ạl'ạly, Ạlktạb Ạlạhṣạ̉y Ạlsnwy Lmw̉ssạt Ạlt'lym Ạl'ạly Ạlflsțynyh, Rạm Ạllh, (2017/2018)

[26] Ywsf. Ảymn Ṭlạl, Ạ̉trwhạt Ạlhrkh Ạlțạbyh Fy Ạljạm ạt Alflsțynyh Byn Ạlsyạsy Wạlmṭlby :Qrạ'h Nqdyh Fy Ạlslwk Wạlmmạrsh, Wrqü Bḥth Mnshwwrh, Jnyn: Ạljạm'h Ạl'rbyh Ạlạ̉mrykyh, (2013m). 